Pensares em Revista, ISSN 2517-2215

\title{
PROUST COMO LEITOR E A SALA DE AULA
}

Ana Luiza Ramazzina GHIRARDI

(Universidade Federal de São Paulo)

alramazzina@uol.com.br

Resumo: Este artigo discute o lugar da literatura nas aulas de línguas, apresentando uma estratégia para a utilização de Contre Sainte-Beuve, de Marcel Proust, como uma ferramenta para desenvolver habilidades de escrita e fomentar a autonomia do aprendiz. Para isso, em um primeiro momento, é feita uma análise de como Proust leu o método de Sainte-Beuve e como seu olhar trouxe uma nova perspectiva para entender o eu narrador de um texto literário. Em seguida, essa experiência é transferida para a sala de aula a partir de um texto do próprio Proust, a Madeleine, buscando levar o aprendiz a experimentar a mesma experiência do narrador da Recherche. O aprendiz será o centro dessa experiência e se deixará conduzir, a seu modo, pela redação proustiana. Para isso, busca-se problematizar a atitude do aprendiz-leitor frente ao texto literário e fazê-lo, a partir de seu olhar, reconstruir o texto que the é apresentado.

Palavras-chave: Leitura. Aprendiz-Leitor. Produção Escrita. Proust. Sainte-Beuve.

Abstract: This article discusses the place of literature in language classes by presenting a strategy to use Marcel Proust's Contre Sainte-Beuve as a tool to develop writing abilities and to create autonomous learners. It starts by examining Proust's reading of Sainte-Beuve's literary criticism and the ways in which Proust's critique has contributed to a new understanding of the relations between texts. The next section brings Proust's text (the Madeleine excerpt) to the classroom and explains how it can lead students to experience the type of insight described by the author of Recherche. The learner will be the center of this experience and will be invited to build up a personal response to Proust's narrative. The sequence of activities designed to help qualify such response is the object of the last section of this paper.

Keywords: Reading. Learner-Reader. Writing. Proust. Sainte-Beuve. 


\section{Proust leitor: para entender o método Sainte-Beuve}

Por que Proust e o método Sainte-Beuve ainda nos interessam nos dias de hoje? Como um método crítico, concebido no século XIX, pode auxiliar o percurso de um jovem aprendiz a compreender de forma melhor o texto literário que a ele se apresenta e buscar diferentes sentidos nessa narrativa? Como esse texto pode contribuir para a sua formação em uma língua estrangeira e criar um universo plurilíngue?

Nosso percurso tem início no século XX, quando Proust buscava desvendar o que Sainte-Beuve pregava ser sua estética crítica. É de 1907 e 1908, quando Marcel Proust ainda era um jovem escritor desconhecido, que datam os ensaios a respeito do método de Sainte-Beuve ${ }^{1}$, Contre Sainte-Beuve. ${ }^{2}$ Graças a Bernard de Fallois, que reúne e publica os ensaios, pode-se ter acesso ao olhar atento de Proust e verificar que sua leitura sobre o método Sainte-Beuve toma uma dimensão maior do que o primeiro projeto do autor.

Quando da elaboração de seu estudo a respeito de Sainte-Beuve, Proust hesita entre dois tipos de versão para sua realização: a forma clássica (seguindo a mesma linha dos ensaios de Taine) e a narrativa, na qual Proust descreveria uma manhã em que explica à sua mãe em que consiste esse método. $O$ autor decide pela segunda fórmula e, desde as primeiras linhas dessa narrativa, percebe-se claramente que além de criticar o método, Proust está em busca de um projeto maior cujo desfecho seria a concepção de sua obra: Sainte-Beuve torna-se uma forma de evidenciar suas próprias concepções estéticas.

Proust apresenta Sainte-Beuve como um crítico que escreve "dans son temps et pour son temps" (PROUST, 1989, p. 25), já que os famosos Lundis ${ }^{3}$ representavam a crítica como a arte de informar o melhor possível ao público

\footnotetext{
${ }^{1}$ Charles Augustin Sainte-Beuve (1804-1869) foi crítico literário e personagem de destaque na literatura francesa ; criou o método Sainte-Beuve que foi retomado por Jean-Paul Sartre.

${ }^{2}$ Rejeitados por um importante editor da época, os ensaios são apenas editados em 1954 - 32 anos após a morte do autor.

${ }^{3}$ Sainte-Beuve publica semanalmente textos literários em jornais (Le Constitutionnel, Le Moniteur, Le Temps) sob o nome "Causeries du lundi », o título fazia referência à sua publicação semanal sempre lundi (segunda-feira).
} 
sobre diferentes aspectos da obra e de fazer a ligação entre obra e autor. Proust percebe nessa crítica a avaliação de uma obra em relação ao autor e o que lhe é contemporâneo: para Sainte-Beuve, o conteúdo da obra deveria estar necessariamente ligado ao que o autor está vivendo: “à ne pas séparer l'homme de l'œuvre" (idem, p. 127)

A essa visão, Proust contrapõe seu próprio método crítico, que, em oposição, tende a considerar a obra por ela mesma, completamente desligada de qualquer elo biográfico:

(...) cette méthode méconnait ce qu'une fréquentation un peu profonde avec nousmême nous apprend: qu'un livre est le produit d'un autre moi que celui que nous manifestons dans nos habitudes, dans la société, dans nos vices. Ce moi-là, si nous voulons essayer de le comprendre, c'est au fond de nous-mêmes, en essayant de le recréer en nous, que nous pouvons y parvenir. (idem, p. 127, grifo nosso)

Seguindo a linha de Bergson, que distingue o "eu social" do "eu profundo", Proust está convencido de que toda a riqueza de uma narrativa pode ser alcançada independente de qualquer nota biográfica a respeito do autor. Proust abre caminho para uma diversificação de relações entre o "eu" e a obra; ele percebe o perigo do método Sainte-Beuve quando este confunde o "eu social" e o "eu criador" e parte em busca de estruturas temáticas profundas. Segundo Proust, um livro é produzido por um outro "eu" inacessível ao estudo biográfico e que só é possível compreender tentando recriá-lo dentro de nós.

Proust acredita ainda que em arte não há iniciador, ele acredita na originalidade absoluta do artista criador e recoloca o problema sob outra luz: o que importa realmente é a singularidade da frase e não a originalidade do estilo e as causas de sua criação; o artista se encontra sempre em um ponto de partida:

Tout dans l'individu, chaque individu recommence, pour son compte, la tentative artistique ou littéraire ; et les œuvres de ses prédécesseurs ne constituent pas, comme dans la science, une vérité acquise, dont profite celui qui suit. Un écrivain de génie aujourd'hui a tout à faire. II n'est pas beaucoup plus avancé qu'Homère. (idem, p. 124)

Proust continua sua crítica ao método analítico de Sainte-Beuve ao citar um fragmento de La critique littéraire, base de la Science morale (Nouveaux Lundis, 
22 juillet 1862 - Sainte-Beuve) e destacar que Sainte-Beuve encontra problemas com os clássicos "on n'a pas les moyens suffisants d'observation. 》Ele acredita ali encontrar o melhor da crítica de Sainte-Beuve, já que ele se vê reduzido a comentar a obra, a admirá-la, a sonhar o autor e o poeta unicamente através da obra. Já com os modernos, sua crítica era diferente, ele sabia exatamente como avaliar a obra:

La littérature, disait Sainte-Beuve, n'est pas pour moi distincte ou, du moins, séparable du reste de l'homme et de l'organisation... On ne saurait s'y prendre de trop de façons et de trop de bouts pour connaître un homme, c'est-à-dire autre chose qu'un pur esprit. Tant qu'on ne s'est pas adressé sur un certain nombre de questions et qu'on n'y a pas répondu, ne fût-ce que pour soi seul et tout bas, on n'est pas sûr de le tenir tout entier, quand même ces questions sembleraient les plus étrangères à la nature de ses écrits : Que pensait-il de la religion ? Comment était-il affecté du spectacle de la nature ? Comment se comportait-il sur l'article des femmes, sur l'article de l'argent? Était-il riche, pauvre; quel était son régime, sa manière de vivre journalière ? Quel était son vice ou son faible ? Aucune réponse à ces questions n'est indifférente pour juger l'auteur d'un livre et le livre lui-même, si ce livre n'est pas un traité de géométrie pure, si c'est surtout un ouvrage littéraire, c'est-à-dire où il entre de tout. (idem, p. 126)

Ao contrário de Sainte-Beuve, que julga poder fazer boas críticas a respeito dos modernos pois o seu método consiste em não separar o homem e a obra, Proust enxerga exatamente nesse ponto a falha do método proposto. Enquanto Sainte-Beuve supõe que, ao seguir um questionário, possa bem julgar as obras contemporâneas, Proust acredita que um livro é produto de um outro "eu" que o crítico não soube descobrir.

Assim, Proust mostra os riscos desse método que destaca o "eu social" e ignora o "eu criador" e que despreza a ideia da criação literária como produto de um outro "eu" diferente daquele manifestado na sociedade. Segundo Proust, o que importa é o "eu criador" (e não o "eu social") e ele só é possível de ser compreendido quando recriado dentro de nós e não quando procurado no mundo exterior.

Proust acredita que em nenhum momento Sainte-Beuve compreendeu o que há de particular na inspiração e no trabalho literário, nem o que diferencia completamente esse trabalho das ocupações dos outros homens e das ocupações do próprio escritor. Sainte-Beuve não encontra fronteiras entre a ocupação literária 
e a causerie", para ele o "eu criador" (aquele que se tranca em sua obra) é o mesmo que o "eu social" (aquele que vive e fala em sociedade).

Segundo Proust, Sainte-Beuve não é capaz de reconhecer o mundo particular da alma do poeta que não tem comunicação com o mundo exterior, ele não compreende o abismo entre o "eu criador" e o "eu social" porque não compreende que esse "eu criador" está confinado aos livros, não frequentando a sociedade. Tudo o que se pode saber através de amigos, artigos ou do próprio escritor são elementos dispensáveis ao "eu" verdadeiro do poeta. Esse método, segundo Proust, acaba por aprisionar o seu criador, visto que ele só se encontra em plena liberdade para fazer sua crítica se desprendido de qualquer laço com o autor do objeto criticado. É por isso que Proust julga a crítica de Sainte-Beuve inconsistente.

Contudo, Proust não recusa a Sainte-Beuve certo mérito já que ele vê no crítico um espírito curioso, capaz de mostrar seu pensamento pessoal toda semana aos seus leitores, cumprindo assim a tarefa de trazer novos conhecimentos à sociedade. Proust reconhece a sutileza com que o crítico trouxe em sua obra crítica uma espécie de "breviário" do século XIX intelectual e cultivado, o que lhe valeu o título de mestre inigualável da crítica desse mesmo século.

\section{Proust leitor: Proust escritor}

A partir da submissão voluntária a um universo que não o seu, Proust encontra o caminho para a elaboração de uma concepção de literatura que será a fonte da Recherche: se o estilo "é uma questão não de técnica, mas de visão" 5 é que a arte de escrever, em cada criador, coincide com a agudeza de uma percepção original. A crítica aparece na vida de Proust como uma iniciação à sua obra propriamente dita, ela faz parte de sua criação. Assim, o autor surge como um precursor de um novo modo de realizar uma obra. A crítica, que até esta

${ }_{5}^{4}$ Causerie : entretien familier, conversation (Le Robert Quotidien, 1996)

5 "le style pour l'écrivain aussi bien que pour le peintre est une question non de technique, mais de vision" (Proust, 1989, p. 474) 
época aparecia em segundo plano em relação à obra, em Proust aparece simultaneamente. Proust encontra ainda o elemento essencial de sua obra, "o narrador", o personagem "que diz: eu", é ele que vai conduzir toda a obra, é ele que vai conseguir finalmente ligar as ideias opostas do mesmo autor, até então dispersas em textos diversos.

O estudo do método Sainte-Beuve começa por pequenas anotações, avoluma-se e flui para o grande projeto da Recherche. Quando Proust adota, como já foi dito, a segunda forma de escrever a respeito do método de SainteBeuve, concebe o prefácio que posteriormente tornar-se-ia Le côte de chez Swann (primeiro volume da Recherche) e o posfácio, Le temps retrouvé (último volume da Recherche).

Mesmo a figura de Sainte-Beuve é aproveitada na Recherche quando podese encontrar sua caricatura na personagem de Mme de Villeparisis (personagem que se acredita grande conhecedora dos românticos por esses frequentarem a casa de seu pai) em A l'ombre des Jeunes Filles en Fleurs (segundo volume da Recherche). O estudo do método de Sainte-Beuve representa na vida de Proust o momento em que suas ideias, seus projetos, seus trabalhos se organizam em volta do mesmo objeto: a questão do "eu criador" e do "eu social".

O Contre Sainte-Beuve reverte, ou subverte, a partir do interior, a concepção da crítica biográfica então em voga e permite a Proust encontrar caminho para a elaboração de uma concepção de literatura: a arte de escrever, em cada criador, como já se mencionou, coincide com a agudeza de uma percepção original.

A atitude crítica de Proust tem, dessa forma, um movimento dialético: à tese de Sainte-Beuve (a obra se justifica pelo autor) opõe-se a antítese (o autor não é o "eu social”) da visão proustiana que irá produzir uma nova concepção (síntese: o autor é um outro eu, o eu criador) do fazer literário. Neste fazer literário, o "eu narrador", em sua multiplicidade de perspectivas e em suas diferentes maneiras de produzir sentidos, torna-se o fio condutor da narrativa. 


\section{Proust e a sala de aula}

Tomando como partida a ideia de multiplicidade, de pluralidade de sentidos característica de qualquer texto, sobretudo do literário - que Proust soube como ninguém explorar ao analisar o método Sainte-Beuve e, mais tarde, em sua narrativa - nosso percurso continua na sala de aula de língua francesa imitando essa prática. $O$ aprendiz será o centro dessa experiência e se deixará conduzir, a seu modo, pela redação proustiana. Para isso, um trabalho a partir de competências integradas será de grande utilidade e ajudará o aprendiz a desenvolver duas aptidões: compreensão e produção escritas. Pendanx sublinha que levar o aprendiz a efetuar duas tarefas concomitantes o aproxima de sua atitude cotidiana frente ao mundo:

Pour habituer l'apprenant à traiter plusieurs opérations simultanément et à gérer diverses contraintes, on lui proposera des activités globalisantes, qui unissent deux compétences (ou plus) à la fois. II se trouvera ainsi dans des situations de parole proches de la vie courante. De plus, portant son attention sur plusieurs aspects de la tâche, il s'entraînera à traiter simultanément certaines opérations de bas niveau en production orale ou écrite. (PENDANX, 1998, p. 122)

Ainda em relação à competência escrita, Pendanx observa que ela é lugar privilegiado da observação e da reflexão sobre a língua (idem, p. 123). O texto proustiano usado nessa atividade ajudará o aprendiz a refletir sobre aspectos da língua escrita através de uma passagem corriqueira: um menino, ao levar à boca um pedaço de bolo que havia molhado no chá, experimenta um momento de reminiscência.

A partir desse texto, o aprendiz é conduzido, de modo informal, para a composição de um texto que ele produzirá em resposta a essa escritura que se apresenta como um modelo proposto. Assim como Proust, que a partir da leitura do método crítico de Sainte-Beuve concebe seu próprio texto, o aprendiz partirá de um trecho de $\dot{A}$ la recherche du temps perdu para experimentar seu fazer literário a partir de seu olhar.

O primeiro passo é, portanto, a problematização da atitude do aprendiz-leitor frente ao texto literário. $O$ texto não deve ser visto como objeto pronto e fechado, 
de sentido único e inquestionável. É o olhar do aprendiz (como fora o olhar de Proust) que, em última análise, construirá o sentido do texto. Nas palavras de Genette: Un livre n'est pas un sens tout fait, une révélation que nous avons à subir, c'est une réserve de formes qui attendent leur sens. (Gérard Genette in TAGLIANTE, 2006, p. 173)

Caberá ao aprendiz buscar nas formas da narrativa um sentido para o texto, ele tomará consciência da importância do "eu criador" nesse momento; será preciso recriar dentro de cada um a disponibilidade da criação de uma nova frase mesmo que essa apareça como resposta a um texto já conhecido e utilizado.

O aprendiz deixará se levar por um mundo que não o seu - o do texto literário de um escritor reconhecido - e encontrará caminhos para a concepção de seu próprio texto; a sua escritura será um momento de criatividade e de originalidade, pois a sua percepção será única. É nesse momento que o aprendiz será convidado a "experimentar", pela prática, como se disse, a atitude proustiana de recriação.

\section{4. $O$ aprendiz se apropria do texto: a madeleine de Proust}

No manual Tempo 2, há uma proposta de atividade ${ }^{6}$ a partir de um texto literário que se tornou famoso: la madeleine, de Proust. $O$ método em questão propõe uma discussão (produção oral) a respeito da diferença de percepção cultural de odores e um questionamento sobre a experiência ou não do aprendiz a partir daquela do narrador proustiano. Em geral, os textos literários aparecem em métodos de FLE como uma atividade extra, que pode ou não ser realizada pelo aprendiz.

Essa atividade é inspirada nessa página do método a partir do recorte que os autores fizeram do trecho ${ }^{7}$ do romance Du côté de chez Swann, de Marcel Proust, para propor uma atividade de compreensão escrita e uma de produção escrita intercruzadas. Acredita-se que o texto literário, mais do que figurar como uma

\footnotetext{
${ }^{6}$ BÉRARD, É., CANIER, Y., LAVENNE, C. Tempo 2. Paris : Les Éditions Didier, 1997, p. 242

${ }^{7} \mathrm{O}$ texto de Proust com o recorte proposto pelo método Tempo 2 encontra-se no final desse artigo sob forma de anexo.
} 
ferramenta "a mais" para a aprendizagem, é capaz de trazer para a sala de aula e para o aprendiz situações únicas em sua experiência de aprendizado, buscando uma perspectiva autônoma. A partir de um dos textos mais famosos da literatura francesa, a madeleine de Proust, o aprendiz será colocado diante de uma escritura que não a sua e de reconhecimento de todos.

O trabalho tem início com uma atividade de pré-leitura que ajuda o aprendiz a antecipar algumas informações que não fazem parte de seu cotidiano. Como se trata de outra cultura, a francesa, torna-se importante a familiaridade do aprendiz com as novas informações que estarão presentes no texto abordado e que não compõem o foco principal da narrativa. Cuq e Cruca nos assinalam a importância da pré-leitura:

[...] l'étape de la prélecture peut reposer sur des activités ludiques à partir d'un mot thème ou sur des mots pivots qui permettent d'anticiper le contenu du texte ou faciliter la lecture. Ces activités, conduites sous la forme d'un remue-méninges, consistent donc à pré-dire le texte et créent un horizon d'attente propice à une meilleure réception du texte: la lecture invalidera le scénario dressé par la formulation d'hypothèses par l'apprenant et par le groupe classe et établira une interaction intime entre l'objet texte et le lecteur» (CUQ \& GRUCA, 2005. p. 421).

As atividades de pré-leitura, em geral, devem se apresentar de forma simples e levar o aprendiz a sentir prazer nesse momento em relação à tarefa solicitada. Para esse texto, o aprendiz é solicitado, a partir de uma imagem de Combray, a imaginar como é a cidade e fazer uma lista de adjetivos para caracterizá-la. Em seguida, o aprendiz deve fazer uma pesquisa na Internet sobre a famosa Madeleine e o chá de tília. Com esses elementos que fazem parte do cenário cultural francês mas que escapam à compreensão do leitor brasileiro (Combray, uma comuna na Normandia, Madeleine, um bolinho típico francês e o chá de tília, popular na França como o de erva-doce no Brasil), o aluno começa a leitura de modo mais confortável e consegue iniciar, mesmo antes de ler o texto, um trabalho de troca cultural: a sua e a francesa.

Num primeiro momento, o texto retrata uma situação fácil de ser imaginada pelo leitor: em um dia de inverno, a mãe oferece ao filho chá com bolo na tentativa de ajudá-lo a combater noites de insônia. Mas é a partir desse ato corriqueiro que 
o narrador introduz um momento singular da narrativa e que desviará a visão do aprendiz-leitor de forma marcante: o sabor da madeleine causa ao narrador um delicioso prazer, sem explicação que desvela um "eu" até então desconhecido e que lhe proporciona uma grande alegria. Esse sabor da madeleine com chá é capaz de transportá-lo a Combray e fazê-lo experimentar diversas sensações ali um dia vividas.

Após essa primeira leitura seletiva ${ }^{8}$ em que o leitor identifica rapidamente a ideia principal (a ativação da memória através de um dos sentidos), o aprendiz é solicitado a preencher um quadro simples com informações sobre o texto (personagens, ações, tempo, sensações, transformações, lugares).

Adam, em Langue et Littérature, sublinha que:

La lecture tabulaire a pour but de rendre littéralement visible la 'géométrie' complexe qui définit chaque personnage et chaque situation. Cette lecture vise, de plus, à briser le rapport intimidé des apprenants avec l'écorce intouchable du texte classique. II s'agit de changer certains réflexes de lecture en mettant en cause le trop grand naturel de la linéarité de l'approche habituelle d'une œuvre. En insistant sur certains aspects de la fabrique du texte, il s'agit de privilégier la découverte, la déduction, la formulation d'hypothèses à vérifier par une micro-analyse. (ADAM, 1991, p. 192)

A ajuda do quadro sinóptico, com levantamentos de dados, informações que se revelam mais claras quando isoladas, auxiliará a compreensão dessa passagem a partir de sua linguagem, analisando a intenção do narrador ao montar um cenário particular para introduzir a transformação final vivida pelo narrador.

Em seguida, o aprendiz é solicitado a preencher um novo quadro, dessa vez com os elementos contidos em um bol de porcelana e uma xícara de chá que servirá para fechar a narrativa desse trecho com 0 desencadeamento da transformação vivida pelo narrador.

Em uma primeira etapa, o texto é explorado pelo aprendiz, que descobrirá em Proust uma nova leitura possível aos seus olhos e que trará para sua experiência literária uma nova perspectiva de leitor: o eu narrador traz para o leitor

\footnotetext{
${ }^{8}$ Tagliante chama esse tipo de leitura de lecture écrémage: aller à l'essentiel, trouver les mots clés significatifs de ce qui est important ou nouveau. Définir le type de texte et sa fonction. (Tagliante, 2006, p. 136)
} 
a história de um menino que volta para casa com frio e a mãe propõe uma xícara de chá para aquecê-lo. Envolvido pelas palavras de Proust, o leitor é capaz de transportar para sua leitura a transformação pela qual o narrador instantaneamente passa ao colocar em sua boca um pedaço de bolo. A partir de então, o questionamento do narrador se torna o questionamento do leitor: "D’où avait pu me venir cette puissante joie? D'où venait-elle? Que signifiait-elle? Où l'appréhender?'9

O aprendiz se encontra com o mesmo questionamento e busca respostas, ele encontrará no texto e nos quadros que construiu a ajuda necessária para responder a cada uma dessas perguntas. O aprendiz-leitor já foi capturado pelo narrador que lhe deu as respostas: o gosto provinha do bolinho que a tia do garoto Ihe oferecera bem cedo em Combray, quando ele Ihe dava bom dia em seu quarto. Ao entender que o gosto encontra origem nesse episódio, o narrador transporta para aquele momento todo o mundo de Combray que, segundo ele, saía de sua xícara de chá (est sorti de ma tasse de thé). Além de compreender a situação cotidiana, o aprendiz é capaz de perceber o quanto esse momento é positivo pois o narrador compara tudo o que revê a um jogo japonês que alegra e transforma simples pedaços de papel em cores, flores, casas, personagens.

O narrador proustiano, com extrema sutileza, é capaz de oferecer ao aprendiz-leitor, através de uma narrativa complexa, a simplicidade de um momento agradável de reminiscência que poderia ser vivido por qualquer um de nós. O aprendiz é capaz de perceber isso, recriar esse momento em seu próprio espaço e compreender o significado da narrativa.

Eliane Papo (1989, pp. 18-19) ressalta que a partir de uma abordagem que desmonta o objeto construído que é o texto, pode-se descobrir normas partilhadas pelos participantes da comunicação literária da qual os leitores (incluindo os aprendizes) são parte integrante. Essa abordagem pretende fazer com que o aprendiz tome consciência de algumas regularidades no texto a partir das quais é possível distinguir diferentes características. $\mathrm{Na}$ passagem aqui apresentada, regularidades relativas ao personagem e suas sensações são

\footnotetext{
${ }^{9}$ Verificar citação no texto anexo no fim desse artigo.
} 
verificadas. Com a ajuda de elementos textuais isolados por quadros sinópticos, é possível desmembrar o texto para que o aprendiz possa reconstruir o seu sentido a partir do seu olhar.

Como já foi dito anteriormente, ao desmontar o texto, surge a possibilidade de fazer emergir diferentes aspectos não revelados em uma leitura linear. Quando se lê um texto literário através de uma abordagem que privilegia seu aspecto linguajar, pretende-se não apenas desenvolver a capacidade de leitura do aprendiz mas também sensibilizá-lo ao aspecto cultural da língua alvo.

A leitura feita aqui pode ajudar o leitor-aprendiz a compreender melhor 0 texto, uma vez que os exercícios contribuem para acentuar sua capacidade de descobrir e fruir melhor do lado linguístico da construção literária.

\section{Imitando Proust}

A relevância do texto escolhido é sua característica autônoma: ele se apresenta de forma que possa ser lido e apreciado mesmo que o leitor ignore a existência da obra de Proust ou que não tenha ouvido falar do bolinho chamado madeleine; o aprendiz-leitor será capaz de compreender a situação descrita sem a necessidade de explicações sobre o que aconteceu antes ou o que vai acontecer depois desse fragmento.

Após esse trabalho de compreensão escrita, o nosso percurso se conclui com o aprendiz pronto para trabalhar a segunda competência proposta, a produção escrita. O aprendiz se apropriará desse texto e trará para seu "eu" a experiência vivida pelo narrador, fazendo dessa experiência a sua.

A experiência do narrador proustiano servirá como base para a produção escrita aqui sugerida. Após a leitura do texto, será lançada uma discussão sobre os cinco sentidos (visão, audição, paladar, tato e olfato). Nesse momento o aprendiz estará livre para abordar os mais diferentes modos pelos quais os sentidos se apresentam e essa atividade, sob forma de brainstorming, servirá como um preparo para a atividade escrita. A partir dessa prática, uma rede lexical será formada e será útil ao aprendiz no momento em que ele compuser seu texto. 
Em seguida, a palavra "reminiscência" será abordada e uma discussão sobre já ter tido ou não um momento de reminiscência será o centro do debate.

Com uma rede lexical formada, o aprendiz recriará um novo texto baseado em reminiscências próprias (ou imaginadas) criadas por um dos cinco sentidos; como Proust experimentou experiências tendo como fonte o paladar, o aprendiznarrador experimentará experiências a partir de um dos sentidos. $O$ aprendiz pode se valer de experiências pessoais ou de fatos por ele conhecidos que consigam trazer para o texto a mesma ideia de reminiscência do narrador proustiano. O que importará nesse exercício é a disposição de o aprendiz de mergulhar em seu universo e de trazer para a sua frase um novo universo criativo que ninguém seria capaz de compor, nem mesmo Proust.

Para lá da expansão e refinamento das habilidades de compreensão e produção escrita, esta atividade contribui também para o aprimoramento da capacidade dos aprendizes de se apropriarem criticamente da literatura. Muitas vezes, crenças que foram passadas de gerações para gerações são alimentadas e reproduzidas sem questionamentos e reflexões sobre sua validade. Quando o nome Proust é citado, por vezes ecoa o grande desejo de descobrir sua narrativa mas acredita-se na frustrante impossibilidade de fazê-lo dada a complexidade e dificuldade de sua escrita. Trazer um texto desse autor para nossos aprendizes significa abrir caminho para novas descobertas pessoais. O texto proustiano pode ser lido por diferentes leitores, com diferentes compreensões; o que importa é que cada um de nós tenha a oportunidade de encontrar na narrativa um novo sentido para o mesmo texto e descobrir o "eu criador" que se revelará um guia e fará redescobrir em cada frase uma nova versão não apenas do texto, mas também do aprendiz-autor. 


\section{Referências Bibliográficas}

ADAM, . Langue et Littérature. Paris : Hachette, 1991

BÉRARD, É., CANIER, Y., LAVENNE, C. Tempo 2. Paris : Les Éditions Didier, 1997

CUQ, J-P. \& GRUCA, Isabelle. Cours de didactique du français langue étrangère et seconde. Grenoble: PUG. 2005

PAPO, E. \& BOURGAIN, D. Littérature et communication en classe de langue. Paris : Hatier, 1989

PENDANX, Michèle. Les activités d'apprentissage en classe de langue. Paris : Hachette, 1998

PROUST, Marcel. Contre Sainte-Beuve. Paris : Essais Gallimard, 1989

Du côté de chez Swann. Paris : Gallimard, 1988

Le temps retrouvé, Paris : Gallimard, Pléiade, 1989

TAGLIANTE, Christine. La classe de langue. Paris : CLÉ International, 2006

\section{Anexo}

Il y avait déjà bien des années que, de Combray, tout ce qui n'était pas le théâtre et le drame de mon coucher n'existait plus pour moi, quand un jour d'hiver, comme je rentrais à la maison, ma mère, voyant que j'avais froid, me proposa de me faire prendre, contre mon habitude, un peu de thé. Je refusai d'abord et, je ne sais pourquoi, me ravisai. Elle envoya chercher un de ces gâteaux courts et dodus appelés Petites Madeleines qui semblent avoir été moulés dans la valve rainurée d'une coquille de Saint-Jacques. Et bientôt, machinalement, accablé par la morne journée et la perspective d'un triste lendemain, je portai à mes lèvres une cuillerée du thé où j'avais laissé s'amollir un morceau de madeleine. Mais à l'instant même où la gorgée mêlée des miettes du gâteau toucha mon palais, je tressaillis, attentif à ce qui se passait d'extraordinaire en moi. Un plaisir délicieux m'avait envahi, 
isolé, sans la notion de sa cause. II m'avait aussitôt rendu les vicissitudes de la vie indifférentes, ses désastres inoffensifs, sa brièveté illusoire, de la même façon qu'opère l'amour, en me remplissant d'une essence précieuse : ou plutôt cette essence n'était pas en moi, elle était moi. J'avais cessé de me sentir médiocre, contingent, mortel. D'où avait pu me venir cette puissante joie ? Je sentais qu'elle était liée au goût du thé et du gâteau, mais qu'elle le dépassait infiniment, ne devait pas être de même nature. D'où venait-elle ? Que signifiait-elle ? Où l'appréhender? Je bois une seconde gorgée où je ne trouve rien de plus que dans la première, une troisième qui m'apporte un peu moins que la seconde.

$[\ldots]$

Et tout d'un coup le souvenir m'est apparu. Ce goût, c'était celui du petit morceau de madeleine que le dimanche matin à Combray (parce que ce jour-là je ne sortais pas avant l'heure de la messe), quand j'allais lui dire bonjour dans sa chambre, ma tante Léonie m'offrait après l'avoir trempé dans son infusion de thé ou de tilleul.

$[\ldots]$

Et dès que j'eus reconnu le goût du morceau de madeleine trempé dans le tilleul que me donnait ma tante $[\ldots]$, aussitôt la vieille maison grise sur la rue, où était sa chambre, vint comme un décor de théâtre s'appliquer au petit pavillon, donnant sur le jardin, qu'on avait construit pour mes parents sur ses derrières [...] ; et avec la maison, la ville, depuis le matin jusqu'au soir et par tous les temps, la Place où on m'envoyait avant déjeuner, les rues où j'allais faire des courses, les chemins qu'on prenait si le temps était beau. Et comme dans ce jeu où les Japonais s'amusent à tremper dans un bol de porcelaine rempli d'eau, de petits morceaux de papier jusque-là̀ indistincts qui, à peine y sont-ils plongés s'étirent, se contournent, se colorent, se différencient, deviennent des fleurs, des maisons, des personnages consistants et reconnaissables, de même maintenant toutes les fleurs de notre jardin et celles du parc de M. Swann, et les nymphéas de la Vivonne, et les bonnes gens du village et leurs petits logis et l'église et tout Combray et ses environs, tout cela qui prend forme et solidité, est sorti, ville et jardins, de ma tasse de thé. (Marcel Proust, Du côté de chez Swann, pp. 44-47) 
Artigo recebido em : 09/12/2013

Artigo avaliado em : 14/04/2014

\section{Sobre a autora :}

Professora Adjunta na área de língua e literatura francesa do departamento de letras da Escola de Filosofia, Letras e Ciências Humanas da Universidade Federal de São Paulo. 